\title{
Effects of UV Radiation on Oxidative Stress in Yellowtail Clownfish Amphiprion clarkii
}

\author{
Han Seok Ryu ${ }^{1}$, Cheol Young Choi ${ }^{1 *}$, Jin Ah Song ${ }^{1}$, and Gyung-Suk Kil ${ }^{2}$ \\ ${ }^{I}$ Division of Marine BioScience, College of Ocean Science and Technology, Korea Maritime and Ocean University, Busan 49112, Korea \\ ${ }^{2}$ Division of Electronics Engineering, College of Engineering, Korea Maritime and Ocean University, Busan 49112, Korea
}

Received 13 August 2018; Revised 20 December 2018; Accepted 14 January 2019

(C) KSO, KIOST and Springer 2019

\begin{abstract}
$\overline{\text { Abstract - We investigated oxidative stress under UV radiation }}$ $(380 \mathrm{~nm})$ at two intensities $\left(0.2\right.$ and $\left.0.4 \mathrm{~W} / \mathrm{m}^{2}\right)$ for 14 days $(0,1,3,7$ and 14) in the yellowtail clownfish Amphiprion clarkii. We analyzed mRNA expression and the activity of antioxidant enzymes [superoxide dismutase (SOD) and catalase (CAT)], levels of plasma hydrogen peroxide $\left(\mathrm{H}_{2} \mathrm{O}_{2}\right)$, lipid peroxide (LPO), alanine aminotransferase (AlaAT) and aspartate aminotransferase (AspAT). Furthermore, DNA damage was measured using comet assays and terminal transferase dUTP nick end labeling (TUNEL) assays were performed. As a result, the mRNA expressions and activities of antioxidant enzymes, the levels of plasma $\mathrm{H}_{2} \mathrm{O}_{2}$, LPO, AlaAT and AspAT were significantly higher in the group exposed to UV radiation than the control group. Finally, the comet and TUNEL assay showed that apoptosis was markedly higher at high UV intensity compared to the control group. These results indicate that $U V$ radiation induces oxidative stress and decreases the antioxidant response in yellowtail clownfish.
\end{abstract}

Keywords - oxidative stress, ultraviolet radiation, yellowtail clownfish

\section{Introduction}

The rampant use of chlorofluorocarbon, known as "Freon gas", in recent times has been reducing the ozone levels in the stratosphere and this has caused destruction to the ozone layer. As a result, ultraviolet (UV) radiation levels reaching the surface of the sea at locations between $30-50^{\circ}$ latitudes are increasing (Zagarese and Williamson 2001). Based on their wavelength, UV radiations are classified as UV-A $(320-400 \mathrm{~nm})$, UV-B (290-320 nm), and UV-C (100-290 nm) (Pfeifer and Besaratinia 2012). The depth to which UV radiation penetrates

*Corresponding author. E-mail: choic@kmou.ac.kr the surface of the sea varies with the UV type. Especially, UV-A can penetrate up to a depth of $23 \mathrm{~m}$ beneath the sea surface, whereas UV-B can penetrate up to 7-12 $\mathrm{m}$ (Lesser et al. 2001). The energy per photon of UV that penetrates seawater is higher than that of other wavelengths of light; therefore, the UV that penetrates seawater negatively affects the aquatic organisms, ranging from the primary producers to top-level predators, such as fish, in the ecosystem. Moreover, these radiations are known to damage molecules, in vivo, and induce oxidative stress (Zagarese and Williamson 2001). UV radiations can reach to the depths of coral reefs in coastal areas. The yellowtail clownfish Amphiprion clarkii, which inhabits the coral reefs at depths of 5-20 m can be directly affected by UV-A (Moyer 1976). These are subtropical fish species inhabiting the Pacific and Indian Oceans and coastal areas in Japan (Allen 1975; Fautin and Allen 1992). They are also known to inhabit the coastal area of Jeju Island in Korea (Choi et al. 2013).

UV radiation acts as a stress factor for fish and induces oxidation-reduction reactions, resulting in the production of reactive oxygen species (ROS), which causes oxidative stress in cells and tissues (Pourzand and Tyrrell 1999). Superoxide $\left(\mathrm{O}_{2}{ }^{-}\right)$, hydrogen peroxide $\left(\mathrm{H}_{2} \mathrm{O}_{2}\right)$, hydroxyl radical $\left(\mathrm{OH}^{-}\right)$, and singlet oxygen $\left({ }^{1} \mathrm{O}_{2}\right)$ are representative ROS (Roch 1999).

The overproduction of ROS in the body results in the denaturation of intracellular DNA and proteins, reduces the resistance of organisms to diseases, and induces physiological disturbances, such as decreased reproductive capacity or production of lipid peroxide (LPO) (Kim and Phyllis 1998; Pandey et al. 2003).

Therefore, several organisms, including fishes, activate 
antioxidant mechanisms to protect themselves from oxidative stress, caused by the ROS generated in their body. These mechanisms are mediated by antioxidant enzymes, such as superoxide dismutase (SOD) and catalase (CAT) (Mcfarland et al. 1999). These enzymes especially work in the liver and kidney of fish. SOD is primarily responsible for the removal of ROS by converting $\mathrm{O}_{2}{ }^{-}$to $\mathrm{O}_{2}$ and $\mathrm{H}_{2} \mathrm{O}_{2} \cdot \mathrm{H}_{2} \mathrm{O}_{2}$ produced by SOD is converted to non-toxic $\mathrm{H}_{2} \mathrm{O}$ and $\mathrm{O}_{2}$ by CAT, which is known to have an antioxidant action, and removes ROS (Kashiwagi et al. 1997; Basha and Rani 2003; Hansen et al. 2006).

The oxidative stress and ROS in the body directly increase the level of liver damage. In general, aspartate aminotransferase (AspAT) and alanine aminotransferase (AlaAT) are used as indicators to measure the level of liver damage (Nemcsók and Benedeczky 1990; Choi et al. 2015). Moreover, ROS are known to induce DNA damage and affect apoptosis in fish tissues (Häcker 2000; Kulms and Schwarz 2000).

In the present study, we investigated the effect of the UVA wavelength that penetrates to the depth of yellowtail clownfish habitats to determine how much oxidative stress was induced in fish. We exposed the yellowtail clownfish to two intensities of UV-A $\left(0.2\right.$ and $\left.0.4 \mathrm{~W} / \mathrm{m}^{2}\right)$, which we expected to affect the habitat of this fish at 5-20 m depth based on the observation of Lesser et al. (2000) that the UV intensity reaching $8 \mathrm{~m}$ depth was $0.260 \mathrm{~W} / \mathrm{m}^{2}$. Furthermore, we measured the expression and activity of SOD and CAT mRNA in order to investigate the induction of oxidative stress in yellowtail clownfish depending on the exposure time and the wavelength of UV. To determine the levels of oxidative stress in the body of the fish, we measured the plasma concentrations of $\mathrm{H}_{2} \mathrm{O}_{2}$ and lipid peroxidation (LPO). Moreover, we used comet assays and the terminal transferase dUTP nick end labelling (TUNEL) method to investigate the effects of DNA damage and apoptosis in liver tissues. We also measured AspAT and AlaAT levels, to determine the liver damage level caused by stress.

\section{Materials and Methods}

\section{Fish samples and experimental conditions}

Yellowtail clownfish $(n=200$; length $5.2 \pm 0.5 \mathrm{~cm}$; mass $2.1 \pm 0.5 \mathrm{~g}$ ) were purchased from the Corea Center of Ornamental Reef \& Aquarium (CCORA, Jeju, Korea), and were acclimated for 2 weeks in twelve $300 \mathrm{~L}$ circulation filter tanks in the laboratory. A white fluorescent bulb ( $27 \mathrm{~W})$ was used for the control group, and light intensity at the water surface in the

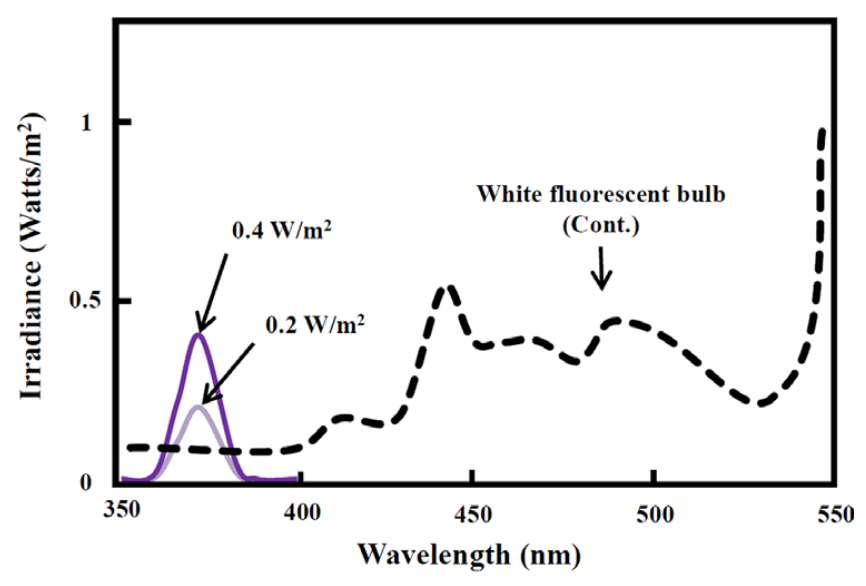

Fig. 1. Spectral profiles of UV radiation (UV $380 \mathrm{~nm}$ ) and white fluorescent bulb (Cont.) used in the present study. Two different intensities were used $\left(0.2\right.$ and $\left.0.4 \mathrm{~W} / \mathrm{m}^{2}\right)$ for each UV treatment

tanks was approximately $0.96 \mathrm{~W} / \mathrm{m}^{2}$. The water temperature was $27 \pm 1^{\circ} \mathrm{C}$ and a 12-h light:12-h dark photoperiod (lights were switched on at 07:00 $\mathrm{h}$ and switched off at 19:00 h) was maintained. The experimental groups of fish were exposed to $\mathrm{UV}$ radiation $(380 \mathrm{~nm})$ at intensities of approximately 0.2 and $0.4 \mathrm{~W} / \mathrm{m}^{2}$ (Fig. 1). The UV source was set $20 \mathrm{~cm}$ above the surface of water and intensities were determined at the middle of water column in the tank, using a spectrometer (MR16; Rainbow Light Technology Co. Ltd., Taoyuan, Taiwan) and Photo-Radiometer(HD 2102.1; Delta OMH Co., Caselle di Selvazzano, Italy). We sampled three fishes from each of the groups at day 0 , day 1 , day 3 , day 7 , and day 14 . The doses of UV radiation on day 0 , day 1 , day 3 , day 7 , and day 14 were $8.64,25.92,60.48$, and $120.96 \mathrm{~kJ} / \mathrm{m}^{2}$, respectively, at an intensity of $0.2 \mathrm{~W} / \mathrm{m}^{2}$ and $17.28,51.84,120.96$, and 241.62 $\mathrm{kJ} / \mathrm{m}^{2}$, respectively, at an intensity of $0.4 \mathrm{~W} / \mathrm{m}^{2}$. The control groups were sampled only on day 0 . All the experiments were repeated thrice. The fishes were anesthetized using 2phenoxyethanol (Sigma, St Louis, Mo, USA) and were decapitated prior to tissue collection. Blood was collected rapidly from the caudal vein using a 1-mL syringe coated with heparin. Plasma samples were separated by centrifugation $\left(4^{\circ} \mathrm{C}\right.$ at $1,000 \times g$ for $\left.15 \mathrm{~min}\right)$, and stored at $-80^{\circ} \mathrm{C}$ until the analysis. The liver tissues were collected from the fish, immediately frozen in liquid nitrogen, and stored at $-80^{\circ} \mathrm{C}$ until the extraction of total RNA.

\section{Total RNA extraction and cDNA synthesis}

Total RNA was extracted from each sample using TRI 
Reagent $^{\circledR}$ (Molecular Research Center, Inc., Cincinnati, OH, USA), according to the manufacturer's instructions. Subsequently, $2 \mu \mathrm{g}$ total RNA was reverse transcribed in a reaction volume of $20 \mu \mathrm{L}$, using an oligo-(dT) $)_{15}$ anchor and M-MLV reverse transcriptase (Promega, Madison, WI, USA), according to the manufacturer's protocol. The resulting cDNA was diluted and stored at $4{ }^{\circ} \mathrm{C}$ for use in PCR and real-time quantitative polymerase chain reaction ( $\mathrm{qPCR}$ ) analysis.

\section{Real-time qPCR analysis}

The qPCR analysis was conducted to determine the relative expression of SOD and CAT, using the total RNA extracted from the liver of yellowtail clownfish. The qPCR primers were designed using the known yellowtail clownfish sequences (Table 1). We conducted qPCR amplification using a Bio-Rad iCycler iQ multicolor real-time PCR detection system (Bio-Rad, Hercules, CA, USA) and iQ SYBR green supermix (Bio-Rad, USA), following the manufacturer's instructions. For control, $\beta$-actin gene was amplified along with each sample, and data were expressed as the difference between corresponding calculated $\beta$-actin threshold cycle (Ct) levels. The $\mathrm{Ct}$ values of the PCR products formed the basis for all analyses. The $\mathrm{Ct}$ levels were defined as the PCR cycle in which the fluorescence signal crossed a threshold during the exponential phase of the amplification curve. The calibrated $\Delta \mathrm{Ct}$ value $(\Delta \Delta \mathrm{Ct})$ of each sample and the internal control ( $\beta$-actin) were calculated as follows: $\left[\Delta \Delta \mathrm{Ct}=2^{\wedge}\right.$ $\left.\left(\Delta C \mathrm{t}_{\text {sample }}-\Delta \mathrm{Ct}_{\text {internal control }}\right)\right]$. After the PCRs were completed, the qPCR data from three replicate samples were analysed using Bio-Rad software to determine the copy numbers of the transcript in each sample.

\section{Analysis of plasma parameters}

Plasma was separated from the whole blood, collected using heparin as an anticoagulant, by centrifugation $\left(4^{\circ} \mathrm{C}\right.$, $1,500 \times \mathrm{g}$, for $15 \mathrm{~min}$ ), and was immediately stored at $-20^{\circ} \mathrm{C}$. The levels of SOD, CAT, and LPO were estimated by immunoassay using ELISA kits (SOD, CSB-E15929fh; CAT, CSB-E15928fh; Cusabio Biotech Co., Ltd., China; LPO, MBS285269; Mybiosource, USA). The $\mathrm{H}_{2} \mathrm{O}_{2}$ levels were measured using a peroxide detect kit (Sigma, USA). The levels of AlaAT and AspAT were determined with a dry multiplayer analytic slide method using a biochemical automatic analyser (Fuji Dri-Chem 4000, Fujifilm, Japan).

\section{Comet assay}

The comet assay is a simple and sensitive technique for quantitatively measuring the DNA damage in eukaryotic cells (Bajpayee et al. 2005). The liver cells $\left(1 \times 10^{5}\right.$ cells $\left./ \mathrm{mL}\right)$ were examined using a CometAssay Reagent kit with singlecell gel electrophoresis assays (Trevigen, Gaithersburg, MD), according to the method described by Singh et al. (1988), with some modifications. The cells were immobilized in agarose gel on CometAssay comet slides and immersed in freshly prepared alkaline unwinding solution for $20 \mathrm{~min}$. Thereafter, the samples were electrophoresed at $18 \mathrm{~V}$ for 30 min, stained with SYBR Green (Trevigen) for $30 \mathrm{~min}$ in the dark, and then observed under a fluorescence microscope (excitation filter 465-495 nm; Eclipse Ci, Nikon, Japan). At least 100 cells from each slide were analysed. For quantification of the results of comet assay, we analysed the percentage of DNA in the tail (tail intensity/total intensity) and tail moment (product of tail length and percentage of DNA in tail), which reflects the amount of DNA damage, using comet assay IV image analysis software (version 4.3.2; Perceptive Instruments Ltd., UK).

\section{Terminal transferase dUTP nick end labelling (TUNEL) assay}

To evaluate the apoptotic response of the fish liver cells to UV radiation, we performed the TUNEL assay using a commercially available in situ cell death detection kit (catalogue number, 11684795 910, Roche, Switzerland). Polylysinecoated slides were used to prevent any loss in the adherence of apoptotic cells to the slides. The fish liver tissue was

Table1. Primers used for qPCR amplification

\begin{tabular}{cll}
\hline \hline Genes (accession no.) & Primer & \multicolumn{1}{c}{ DNA sequences } \\
\hline \multirow{2}{*}{ SOD (JN032591) } & Forward & 5'-CAC GAG AAG GCT GAT GAC-3' \\
& Reverse & 5'-GAT ACC AAT GAC TCC ACA GG-3' \\
\hline \multirow{2}{*}{ CAT (JN032592) } & Forward & $5^{\prime}$-GGG CAA ATT GGT CCT CAA-3' \\
& Reverse & 5'-CGA TGT GTG TCT GGG TAG-3' \\
\hline \multirow{2}{*}{$\beta$-actin (JN039369) } & Forward & $5^{\prime}$-CCA ACA GGG AGA AGA TGA C-3' \\
& Reverse & $5^{\prime}$-TAC AC CAG AGG CAT ACA-3' \\
\hline
\end{tabular}


washed and fixed with $4 \%$ buffered paraformaldehyde and was permeabilised with freshly prepared $0.1 \%$ Triton X-100 and $0.1 \%$ sodium citrate solution. The fixed and permeabilised liver tissue was then incubated with the TUNEL reaction mixture for $1 \mathrm{~h}$ at $37^{\circ} \mathrm{C}$ in a humidified chamber. The slides were washed thrice with phosphate-buffered saline (PBS) and the incorporated biotin-dUTP was detected under a fluorescence microscope (excitation filter 465-495 nm; Eclipse $\mathrm{Ci}$, Nikon, Japan). For paraffin-embedded tissue sections, the slides were dewaxed and fixed according to standard protocols and then treated as described above. The green fluorescent cells indicated apoptosis.

\section{Statistical analysis}

All the data were analysed using the SPSS statistical package (version 19.0; SPSS Inc., USA). A one-way ANOVA followed by Tukey's post-hoc test was used to compare the differences in data $(P<0.05)$. The values are expressed as means \pm standard error (SE).

\section{Results}

\section{Changes in the mRNA expression and activity of SOD and CAT}

The mRNA expression and activities of SOD and CAT
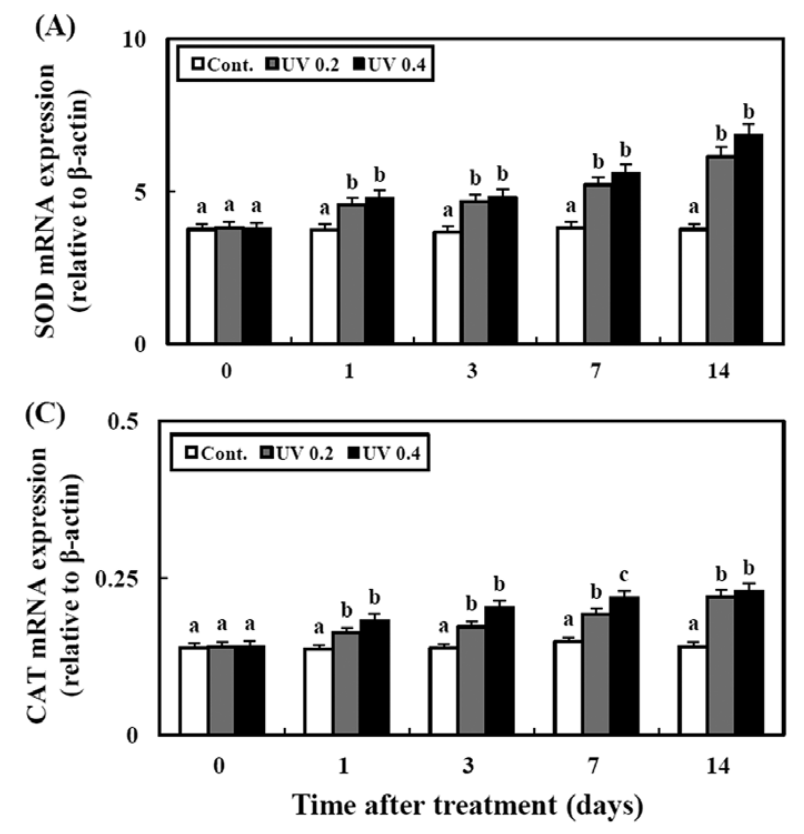

were significantly increased over time in all the groups exposed to UV radiation (Fig. 2). The groups exposed to higher UV intensity $\left(0.4 \mathrm{~W} / \mathrm{m}^{2}\right)$ showed higher mRNA expression and enzyme activities in the plasma than those exposed to lower UV intensity $\left(0.2 \mathrm{~W} / \mathrm{m}^{2}\right)$. However, there were no significant differences in the mRNA levels and enzyme activities in the plasma of fish in the control group.

\section{Changes in the levels of $\mathrm{H}_{2} \mathrm{O}_{2}$, LPO, AlaAT, and AspAT in the plasma}

The levels of $\mathrm{H}_{2} \mathrm{O}_{2}$, LPO, AlaAT, and AspAT in the plasma were significantly increased over time in all the groups exposed to UV radiation (Fig. 3). The fish in the group exposed to higher UV intensity $\left(0.4 \mathrm{~W} / \mathrm{m}^{2}\right)$ had higher mRNA expression and enzyme activities in their plasma than those in the group exposed to lower UV intensity $\left(0.2 \mathrm{~W} / \mathrm{m}^{2}\right)$. However, there were no significant differences in the mRNA expression levels and enzyme activities in the plasma of fish in the control group.

\section{Comet assay}

The damage to liver tissue following 14 days of exposure to UV radiation was analysed using 100 randomly selected cells. Both the DNA content in the tail and tail moment increased significantly with the increase in exposure time in
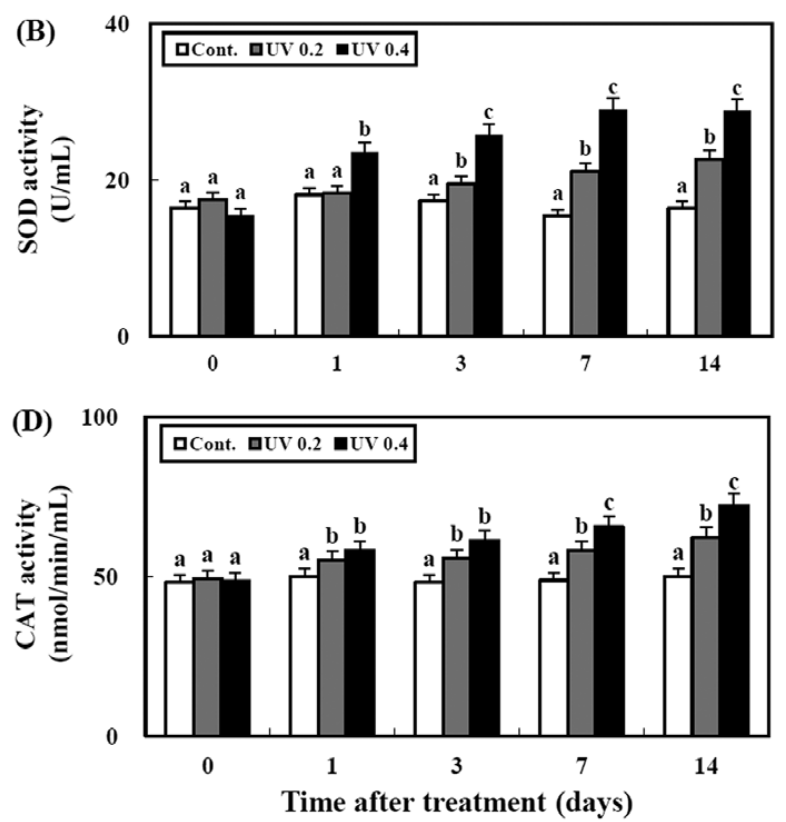

Fig. 2. Changes in the expression of superoxide dismutase (SOD) mRNA (A), SOD activity (B), catalase (CAT) mRNA (C), and CAT activity (D) in yellowtail clownfish exposed to UV radiation at different light intensities $\left(0.2\right.$ and $\left.0.4 \mathrm{~W} / \mathrm{m}^{2}\right)$ and to white fluorescent bulb (Cont.), as measured with a biochemistry auto analyser. The lowercase letters indicate significant differences between the different $\mathrm{UV}$ intensities and control group for the same period of exposure $(P<0.05)$. All the values are means $\pm \mathrm{SE}(n=9)$ 

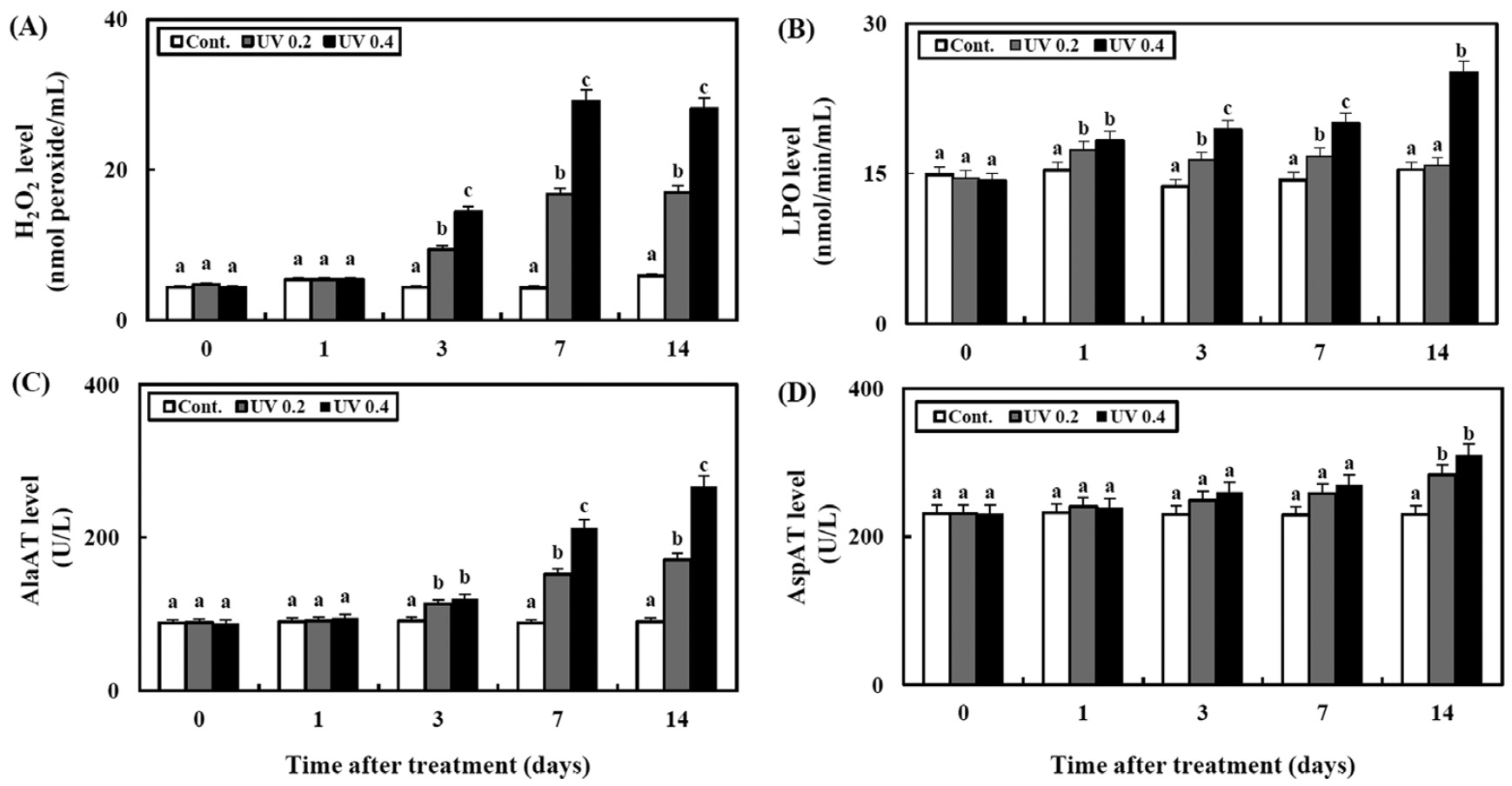

Fig. 3. Changes in the levels of plasma $\mathrm{H}_{2} \mathrm{O}_{2}(\mathrm{~A})$, plasma lipid peroxide (LPO) (B), plasma alanine aminotransferase (AlaAT) (C), and plasma aspartate aminotransferase (AspAT) (D) in yellowtail clownfish exposed to UV radiation at different light intensities $(0.2$ and $0.4 \mathrm{~W} /$ $\mathrm{m}^{2}$ ) and white fluorescent bulb (Cont.), as measured with a biochemistry auto analyser. The lowercase letters indicate significant differences between the different UV intensities and control group for the same period of exposure $(P<0.05)$. All the values are means $\pm \operatorname{SE}(n=9)$
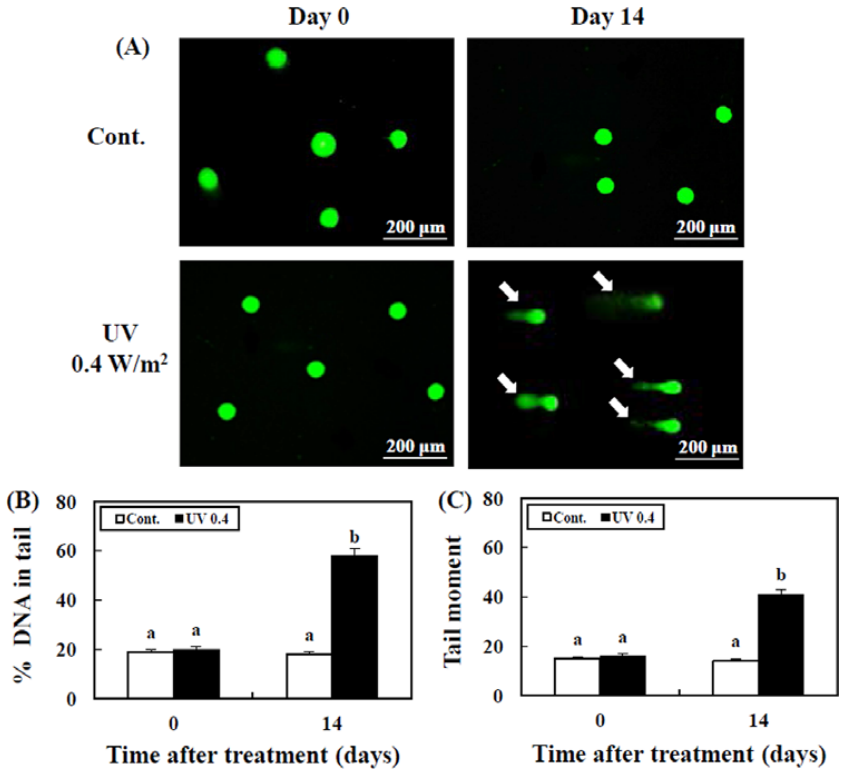

Time after treatment (days)

Fig. 4. Images of comet assay done using liver cells of yellowtail clownfish at the initial condition (at day 0) and after exposure to UV radiation $\left(0.4 \mathrm{~W} / \mathrm{m}^{2}\right.$ on day 14$)$. White arrows in (A) indicate damaged nuclear DNA (DNA breaks) in liver cells, which have been stained with SYBR Gold. Scale bars $=200 \mu \mathrm{m}$. The lowercase letters indicate significant differences between the UV radiation and control groups for the same period of exposure $(P<0.05)$. All the values are mean $\pm \operatorname{SE}(n=9)$

the experimental groups $\left(0.4 \mathrm{~W} / \mathrm{m}^{2}\right)$ compared to their respective values in the control group (Fig. 4). However, there was no significant difference in the control group over time.

Day 0

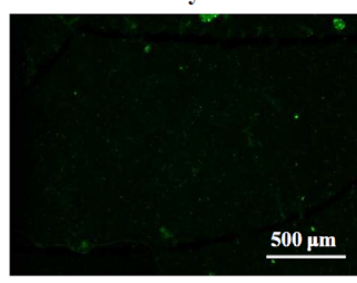

UV $0.4 \mathrm{~W} / \mathrm{m}^{2}$
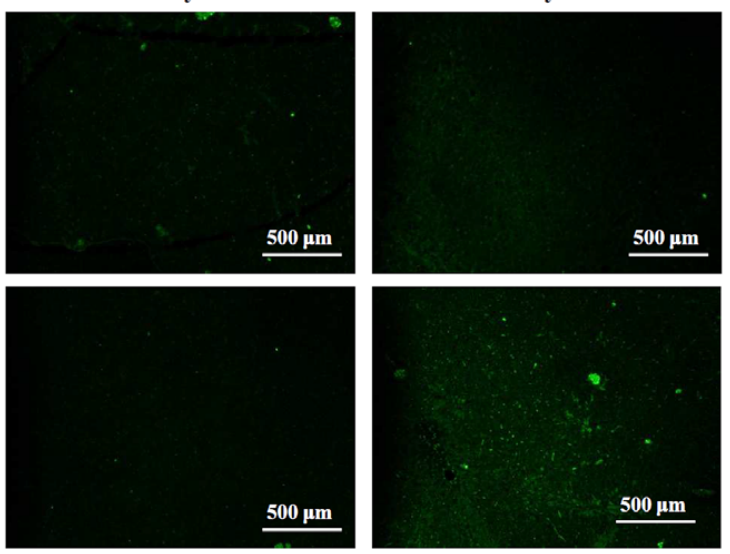

Fig. 5. Images of TUNEL assay done using liver cells of yellowtail clownfish at the initial condition (at day 0 ) and after exposure to $\mathrm{UV}$ radiation $\left(0.4 \mathrm{~W} / \mathrm{m}^{2}\right.$ at day 14$)$. The cells were stained with acridine orange and visualized under a fluorescent microscope. The cells showing green fluorescence are apoptotic cells. Scale bars $=500 \mu \mathrm{m}$ 


\section{TUNEL assay}

The TUNEL assay was used to investigate the presence of apoptotic cells (Fig. 5). We observed significant visible differences among the labelled cells between the control group and the experimental group $\left(0.4 \mathrm{~W} / \mathrm{m}^{2}\right)$. After exposure to UV radiation, the frequency of apoptotic cells was higher than that in the control group.

\section{Discussion}

This study investigated the effects of exposure to UV-A irradiation at two different intensities $\left(0.2\right.$ and $\left.0.4 \mathrm{~W} / \mathrm{m}^{2}\right)$ and for different times on oxidative stress and regulation in yellowtail clownfish.

We determined the mRNA expression and activities of SOD and CAT in yellowtail clownfish exposed to UV-A radiation. The expression of antioxidant genes and activities of antioxidant enzymes in the plasma were significantly increased after UV-A irradiation. In the experimental groups, the expression of SOD and CAT mRNA was not significantly different, but the activity was significantly higher in the experimental group irradiated with $0.4 \mathrm{~W} / \mathrm{m}^{2} \mathrm{UV}-\mathrm{A}$ compared to the experimental group irradiated with $0.2 \mathrm{~W} / \mathrm{m}^{2} \mathrm{UV}-\mathrm{A}$. In a similar study, Lesser et al. (2001) examined the effects of UV on oxidative stress in the larvae of Atlantic cod Gadus morhua after 10 days of exposure to different wavelengths of UV and observed that the SOD activity was significantly higher in the experimental group exposed to UV. They also reported that as the wavelength of UV decreased, the SOD activity in the larvae increased. Charron et al. (2000) investigated the effects of UV on oxidative stress in the body of zebrafish Brachydanio rerio after UV exposure for $25 \mathrm{~h}$, and found that the levels of SOD and CAT mRNA in the skin and muscle samples of the group exposed to UV were significantly higher than those in the skin and muscle of the group not exposed to UV. Likewise, our results showed that in yellowtail clownfish, oxidative stress was induced by UV-A exposure and there was a significant increase in the expression of antioxidant genes as well as in the activities of antioxidant enzymes in the plasma as a way to relieve the stress.

After UV-A irradiation, the concentrations of $\mathrm{H}_{2} \mathrm{O}_{2}, \mathrm{LPO}$, AspAT, and AlaAT in the plasma of yellowtail clownfish were lower in the group exposed to $0.2 \mathrm{~W} / \mathrm{m}^{2} \mathrm{UV}-\mathrm{A}$ than those of the group exposed to $0.4 \mathrm{~W} / \mathrm{m}^{2} \mathrm{UV}$-A. However, there was no significant difference in AspAT concentration.
In a similar study, Zigman and Raffertyt (1994) determined $\mathrm{H}_{2} \mathrm{O}_{2}$ concentration in the lens of dogfish Mustelus canis, after exposure to UV, and found that the decomposition of $\mathrm{H}_{2} \mathrm{O}_{2}$ was reduced in the experimental group exposed to $U V$, which induces oxidative stress. Gouveia et al. (2015) reported that in silverside Odontesthes argentinensis oxidative stress increased the ROS and LPO levels after exposure to UV. They also reported that with the increase in the intensity of $\mathrm{UV}$, the antioxidant capacity in silverside was decreased. Overall, as observed in previous studies, our results show that UV-A exposure induced oxidative stress in yellowtail clownfish, significantly increased the $\mathrm{H}_{2} \mathrm{O}_{2}$, LPO, and AlaAT levels in the plasma, and significantly decreased the antioxidant capacity. Also, based on these results, liver function was found to be degraded.

The degree of DNA damage in the liver tissue of yellowtail clownfish exposed to UV-A irradiation was determined using comet assay. The values of tail length and tail moment of DNA were significantly increased and DNA was found to be damaged in the nucleus of the liver cells of fish in the experimental group irradiated with $0.4 \mathrm{~W} / \mathrm{m}^{2} \mathrm{UV}-\mathrm{A}$ compared to those results obtained for fish in the control group. Sandrini et al. (2009) reported that the mRNA expression of DDB2 and $X P C$, which are genes affecting DNA damage, was increased in the zebrafish Danio rerio upon exposure to UV. Dietrich et al. (2005) exposed the sperm cells of the rainbow trout Oncorhynchus mykiss to UV and performed the comet assay. They found that the values of tail length and tail moment of DNA increased with the increase in the time of exposure to UV. Overall, our results show that the expression of genes affecting DNA damage was increased in yellowtail clownfish after exposure to UV-A, resulting in DNA damage in the liver tissue.

We also determined cytotoxicity in the liver of yellowtail clownfish after UV-A irradiation using TUNEL assay. We noticed a large number of TUNEL-positive cells in fishes exposed to $0.4 \mathrm{~W} / \mathrm{m}^{2} \mathrm{UV}-\mathrm{A}$. Yabu et al. (2001) observed the apoptosis of cells in zebrafish embryos exposed to UV using the TUNEL analysis. They reported the presence of several TUNEL-positive cells in the entire tissue, indicating the induction of cell death, upon UV exposure. The results of TUNEL assay clearly show that UV-A acts as a stress factor in yellowtail clownfish and induces apoptosis.

The results of this study demonstrate that UV-A is a stress factor in yellowtail clownfish, which not only causes DNA damage in liver cells, but also induces apoptosis. Moreover, 
even low intensity $\left(0.2 \mathrm{~W} / \mathrm{m}^{2}\right) \mathrm{UV}-\mathrm{A}$ has a negative effect on the antioxidant defence mechanisms in the yellowtail clownfish and affected the physiology of the fish. Further studies are required to investigate the physiological changes caused by discursive wavelengths and intensities of UV in different fish species; the results of the present study can be used as basic research data for such studies.

\section{Acknowledgments}

This research was supported by the project titled 'Development and commercialization of high density low temperature plasma based seawater sterilization purification system' funded by the Ministry of Oceans and Fisheries, Korea.

\section{References}

Allen GR (1975) The anemone fishes: their classification and biology. T.F.H. Publications, Neptune, $352 \mathrm{p}$

Bajpayee M, Pandey AK, Parmar D, Mathur N, Seth PK, Dhawan A (2005) Comet assay responses in human lymphocytes are not influenced by the menstrual cycle: a study in healthy Indian females. Mutat Res 565(2):163-172

Basha SP, Rani UA (2003) Cadmium-induced antioxidant defense mechanism in freshwater teleost Oreochromis mossambicus (Tilapia). Ecotox Environ Safe 56(2):218-221

Charron RA, Fenwick JC, Lean DR, Moon TW (2000) Ultraviolet$B$ radiation effects on antioxidant status and survival in the zebrafish, Brachydanio rerio. Photochem Photobiol 72(3):327333

Choi YJ, Yang S-G, Jung M-M, Kim B-S, Yun SG, Choi CY (2015) Effects of waterborne selenium on toxic and physiological stress response in goldfish, Carassius auratus. Mol Cell Toxicol 11(1):35-46

Choi Y, Kim B, Lee HH (2013) The fish fauna of little Munsom in Jeju-do, Korea. J Environ Biol 31(1):45-52

Dietrich GJ, Szpyrka A, Wojtczak M, Dobosz S, Goryczko K, Ciereszko A (2005) Effects of UV irradiation and hydrogen peroxide on DNA fragmentation, motility and fertilizing ability of rainbow trout (Oncorhynchus mykiss) spermatozoa. Theriogenology 64(8):1809-1822

Fautin DG, Allen GR (1992) Field guide to anemonefishes and their host sea anemones. Western Australian Museum, Perth, $160 \mathrm{p}$

Gouveia GR, Trindade GS, Nery LEM, Muelbert JH (2015) UVA and UVB penetration in the water column of a South West Atlantic warm temperate estuary and its effects on cells and fish larvae. Estuar Coast 38(4): 1147-1162

Häcker G (2000) The morphology of apoptosis. Cell Tissue Res
301(1):5-17

Hansen BH, Rømma S, Garmo ØA, Olsvik PA, Anderson RA (2006) Antioxidative stress proteins and their gene expression in brown trout (Salmo trutta) from three rivers with different heavy metal levels. Comp Biochem Physiol 143(3):263-274

Kashiwagi A, Kashiwagi K, Takase M, Hanada H, Nakamura M (1997) Comparison of catalase in diploid and haploid Ranarugosa using heat and chemical inactivation techniques. Comp Biochem Physiol 118(3):499-503

Kim MO, Phyllis EB (1998) Oxidative stress in critical care: is antioxidant supplementation beneficial. J Am Diet Assoc 98(9): 1001-1008

Kulms D, Schwarz T (2000) Molecular mechanisms of UVinduced apoptosis. Photodermatol Photo 16(5):195-201

Lesser MP, Farrell JH, Walker CW (2001) Oxidative stress, DNA damage and p53 expression in the larvae of Atlantic cod, Gadus morhua exposed to ultraviolet (290-400 nm) radiation. J Exp Biol 204(1):157-164

Mcfarland VA, Inouye LS, Lutz CH, Jarvis AS, Clarke JU, McCant DD (1999) Biomarkers of oxidative stress and genotoxicity in livers of field-collected brown bullhead, Ameiurus nebulosus. Arch Environ Con Tox 37(2):236-241

Moyer JT (1976) Geographical variation and social dominance in Japanese populations of the anemonefish Amphiprion clarkii. Jpn J Ichthyol 23(1):12-22

Nemcsók J, Benedeczky I (1990) Effect of sublethal concentrations of phenol on some enzyme activities and blood sugar level of carp, Cyprinus carpio L. Environ Monit Assess 14(2-3):377383

Pandey S, Parvez S, Sayeed I, Haques R, Bin-Hafeez B, Raisuddin S (2003) Biomarkers of oxidative stress: a comparative study of river Yamuna fish Wallagoattu (BI.\&Schn.). Sci Total Environ 309(1-3):105-115

Pfeifer GP, Besaratinia A (2012) UV wavelength-dependent DNA damage and human non-melanoma and melanoma skin cancer. Photochem Photobiol 11(1):90-97

Pourzand C, Tyrrell RM (1999) Apoptosis, the role of oxidative stress and the example of solar UV radiation. Photochem Photobiol 70(4):380-390

Roch P (1999) Defense mechanisms and disease prevention in farmed marine invertebrate. Aquaculture 172(1-2):125-145

Sandrini JZ, Trindade GS, Nery LEM, Marins LF (2009) Timecourse expression of DNA repair-related genes in hepatocytes of zebrafish (Danio rerio) after UV-B exposure. Photochem Photobiol 85(1):220-226

Singh NP, McCoy MT, Tice RR, Schneider EL (1988) A simple technique for quantitation of low levels of DNA damage in individual cells. Exp Cell Res 175(1):184-191

Yabu T, Todoriki S, Yamashita M (2001) Stress-induced apoptosis by heat shock, UV and $\gamma$-ray irradiation in zebrafish embryos detected by increased caspase activity and whole-mount TUNEL 
staining. Fisheries Sci 67(2):333-340

Zagarese HE, Williamson CE (2001) The implications of solar UV radiation exposure for fish and fisheries. Fish Fish 2(3): 250-260

Zigman S, Raffertyt NS (1994) Effects of near UV radiation and antioxidants on the response of dogfish (Mustelus canis) lens to elevated $\mathrm{H}_{2} \mathrm{O}_{2}$. Comp Biochem Phys A 109(2):463-467

Publisher's Note Springer Nature remains neutral with regard to jurisdictional claims in published maps and institutional affiliations. 